\title{
Evidence of misery perfusion and risk for recurrent stroke in major cerebral arterial occlusive diseases from PET
}

Hiroshi Yamauchi, Hidenao Fukuyama, Yasuhiro Nagahama, Hidehiko Nabatame, Kazuo Nakamura, Yasumasa Yamamoto, Yoshiharu Yonekura, Junji Konishi, Jun Kimura

Department of Neurology H Yamauch

J Kimura

Y Nagahama

Department of Brain Pathophysiology H Fukuyama

Department of

Radiology and Nuclear Medicine, Faculty of Medicine, Kyoto

University, Kyoto,

Japan

Y Yonekura

J Konishi

Department of

Neurology, Shiga

Medical Center for

Adult Diseases, Shiga,

Japan

H Nabatame

K Nakamura

Department of

Neurology, Kyoto

Second Red Cross

Hospital, Kyoto, Japan

Y Yamamoto

Japan Foundation for Aging and Health, Tokyo, Japan

H Yamauchi

Correspondence to:

Dr H Fukuyama,

Department of Brain

Pathophysiology, Kyoto

University Hospital, 54

University Hospital, 54

Sakyo-ku, Kyoto 606, Japan

Received 25 August 1995

and in final revised form

19 February 1996

Accepted 23 February 1996

\begin{abstract}
Objectives-In major cerebral arterial occlusive diseases, patients with inadequate blood supply relative to metabolic demand (misery perfusion) may be at increased risk for cerebral ischaemia. This study investigated whether patients showing misery perfusion on PET have a high risk of recurrent ischaemic stroke. Methods-The relation between the regional haemodynamic status of cerebral circulation and the subsequent risk of recurrent stroke was prospectively evaluated in 40 patients with symptomatic internal carotid or middle cerebral arterial occlusive diseases who underwent PET. Patients were divided into two haemodynamic categories according to the mean hemispheric value of oxygen extraction fraction in the hemisphere supplied by the artery with symptomatic disease: patients with normal oxygen extraction fraction and those with increased oxygen extraction fraction (misery perfusion). All patients were followed up for at least 12 months.

Results-The one year incidence of ipsilateral ischaemic strokes for patients with normal oxygen extraction fraction and those with increased oxygen extraction fraction were two of 33 and four of seven patients respectively. A significantly higher incidence of ipsilateral strokes was found in patients with increased oxygen extraction fraction (Fisher's exact test; $P=0.005)$. In patients with increased oxygen extraction fraction, three of four strokes were watershed infarctions and the location of the infarction corresponded with the area of increased oxygen extraction fraction.

Conclusion-These findings contradict conclusions of a previous study and suggest that patients with major cerebral arterial occlusive diseases and misery perfusion have a high risk for recurrent ischaemic stroke.
\end{abstract}

\section{$(\mp$ Neurol Neurosurg Psychiatry 1996;61:18-25)}

Keywords: cerebrovascular disease; computed tomography; haemodynamics; stroke risk

In patients with major cerebral arterial occlusive disease, an inadequate blood supply relative to metabolic demand (misery perfusion) may increase the risk of cerebral ischaemia, ${ }^{2}$ suggesting that identification and optimal treatment of patients with misery perfusion could help prevent stroke. However, it remains unclear whether patients with misery perfusion on PET have a high risk of ischaemic stroke, especially strokes of haemodynamic origin. Although case reports and retrospective studies have indicated that bypass surgery relieved patients with misery perfusion from abnormal haemodynamic state and recurring transient ischaemic attacks, ${ }^{134}$ few studies have systematically investigated the relation between cerebral haemodynamics determined by PET and the subsequent risk of stroke. A previous longitudinal study did not find a relation between abnormal cerebral haemodynamics and the subsequent occurrence of stroke, ${ }^{5}$ but the data of the study were limited and not conclusive because of the few patients studied. ${ }^{2}$ To further investigate whether patients with misery perfusion have a high risk of recurrent ischaemic stroke, we prospectively followed up 40 medically treated patients with symptomatic major cerebral arterial occlusive disease who underwent PET.

\section{Methods}

PATIENTS

We followed up 40 patients with symptomatic internal carotid artery (ICA) or middle cerebral artery (MCA) occlusive disease who were under medical treatment. All subjects were prospectively selected from 52 patients with symptomatic ICA or MCA occlusive disease in whom regional cerebral blood flow (CBF), cerebral metabolic rate of oxygen $\left(\mathrm{CMRO}_{2}\right)$, oxygen extraction fraction (OEF), and cerebral blood volume (CBV) were measured using PET at our university hospital between 1985 and 1994. They were consecutive patients who had been referred to the department of neurology from related hospitals for pathophysiological study of major cerebral arterial occlusive diseases using PET. Thus they were not consecutive patients in the related hospitals. Inclusion criteria for the PET studies were as follows: (1) angiographically documented occlusion or stenosis ( $>70 \%$ diameter reduction) of the ICA or MCA; (2) transient ischaemic attacks or minor stroke with mild disability in the arterial distribution distal to the lesion. Exclusion criteria for the follow up study were patients who were scheduled for vascular reconstruction surgery. Seven underwent superficial temporal artery-MCA anastomosis between 1985 and March 1988. During this period, indications 
Table 1 Characteristics of patients at entry

\begin{tabular}{|c|c|c|c|}
\hline \multirow[b]{2}{*}{ Characteristics } & \multirow[b]{2}{*}{ Total group } & \multicolumn{2}{|c|}{ Oxygen extraction fraction } \\
\hline & & Normal & Increased \\
\hline No of patients & 40 & 33 & 7 \\
\hline $\begin{array}{l}\text { Age (y): } \\
\text { Mean } \\
\text { Range }\end{array}$ & $\begin{array}{l}62 \\
41-80\end{array}$ & $\begin{array}{l}62 \\
41-80\end{array}$ & $\begin{array}{l}63 \\
47-74\end{array}$ \\
\hline $\begin{array}{l}\text { Sex: } \\
\text { Male } \\
\text { Female }\end{array}$ & $\begin{array}{l}30 \\
10\end{array}$ & $\begin{array}{r}26 \\
7\end{array}$ & $\begin{array}{l}4 \\
3\end{array}$ \\
\hline $\begin{array}{l}\text { Diagnosis: } \\
\text { Amaurosis } \\
\text { Hemispheric TIA } \\
\text { Minor stroke }\end{array}$ & $\begin{array}{r}1 \\
5 \\
34\end{array}$ & $\begin{array}{r}1 \\
5 \\
27\end{array}$ & 7 \\
\hline $\begin{array}{l}\text { Most recent symptom: } \\
\text { 30-90 Days before PET } \\
\text { 4-12 Months } \\
\text { >1 year }\end{array}$ & $\begin{array}{r}17 \\
16 \\
7\end{array}$ & $\begin{array}{r}13 \\
15 \\
5\end{array}$ & $\begin{array}{l}4 \\
1 \\
2\end{array}$ \\
\hline $\begin{array}{l}\text { Other medical illness: } \\
\text { Hypertension } \\
\text { Diabetes mellitus } \\
\text { Prior MI }\end{array}$ & $\begin{array}{r}20 \\
8 \\
3\end{array}$ & $\begin{array}{r}16 \\
5 \\
3\end{array}$ & $\begin{array}{l}4 \\
3 \\
0\end{array}$ \\
\hline $\begin{array}{l}\text { Angiography: } \\
\text { MCA stenosis } \\
\text { MCA occlusion } \\
\text { ICA stenosis (intracranial) } \\
\text { ICA stenosis (extracranial) } \\
\text { ICA occlusion }\end{array}$ & $\begin{array}{r}1 \\
3 \\
5 \\
2 \\
29\end{array}$ & $\begin{array}{r}1 \\
2 \\
3 \\
2 \\
25\end{array}$ & $\begin{array}{l}1 \\
2\end{array}$ \\
\hline
\end{tabular}

${ }^{\star}$ Most severe angiographic lesion in MCA or ICA ipsilateral to symptoms.

TIA = transient ischaemic attack; $M I=$ myocardial infarction; ICA = internal carotid artery; $\mathrm{MCA}=$ middle cerebral artery

for this surgery were controversial, and these seven patients underwent the surgery after providing informed consent as part of a study to evaluate the haemodynamic and metabolic effects of this surgery, irrespective of cerebral haemodynamics. After March 1988, all patients except those with extracranial ICA stenosis were medically treated. Five patients with unilateral extracranial ICA stenosis underwent carotid endarterectomy between 1988 and 1994, irrespective of cerebral haemodynamics.

The subjects included 30 men and 10 women aged 41 to 80 (mean: 62 (SD) 8 years; table 1). Six patients had had transient ischaemic attacks and 34 had had minor

Figure 1 Relation of the value of oxygen extraction fraction to the value of cerebral blood flow (top) and the ratio of cerebral blood flow to cerebral blood volume ( $C B F / C B V)$ (bottom). Closed circles indicate the six patients with ipsilateral recurrent with ipsilateral recurrent
strokes within the first year of follow up. Dotted lines indicate the upper $95 \%$ confidence intervals for oxygen extraction fraction in the controls.
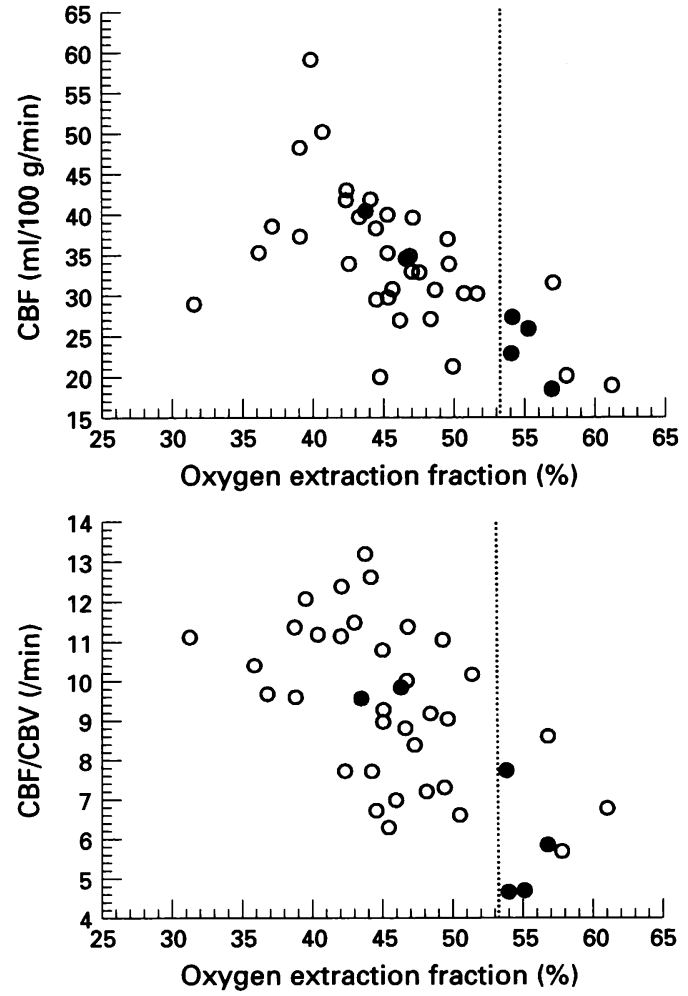

stroke. The intervals between the most recent ischaemic event and PET studies ranged from one to 55 (mean 8 (SD) 11) months. Recurrent symptoms before PET after angiographic demonstration of ICA or MCA disease were identified in only one patient who had intracranial ICA stenosis and experienced orthostatic transient ischaemic attacks despite antiplatelet treatment (patient 1 in table 2). In all patients, CT disclosed only minor abnormalities in the MCA territory or watershed areas of the hemisphere with major arterial disease. Only one patient also had symptoms related to posterior cerebral artery distribution and CT also disclosed a low density area in the posterior cerebral artery territory ipsilateral to major arterial disease. Conventional angiography at the time of the first stroke disclosed unilateral ICA occlusion in 23 patients, unilateral extracranial ICA stenosis (70 and $90 \%$ ) in two, unilateral intracranial ICA stenosis (80, 90,95 , and $95 \%$ ) in four, unilateral MCA occlusion in two, unilateral MCA stenosis $(90 \%)$ in one, ICA occlusion with contralateral extracranial ICA stenosis (50 and $80 \%$ ) in two, ICA occlusion with contralateral intracranial ICA stenosis (65 and $70 \%$ ) in two, MCA occlusion with contralateral extracranial ICA stenosis $(60 \%)$ in one, and bilateral ICA occlusions in three patients. In eight patients with bilateral disease, the symptomatic vascular lesion was unilateral. Of five patients with ICA or MCA occlusion and contralateral ICA stenosis, the lesion involved ICA or MCA occlusion in four patients and intracranial ICA stenosis in one patient. The vertebrobasilar system was angiographically normal in all but two patients. All but two (with extracranial ICA stenosis) patients fulfilled radiological entry criteria for the Extracranial-Intracranial Bypass Trial (stenosis or occlusion of the trunk or major branches before the bifurcation or trifurcation of the MCA; stenosis of the ICA at or above the $C 2$ vertebral body; or occlusion of the ICA), and 17 of 40 patients met the clinical criteria (transient ischaemic attack or stroke within three months before entry). ${ }^{6}$

All patients were treated with antiplatelet therapy (aspirin or ticlopidine $\mathrm{HCl}$ ), but the treatment of risk factors and use of other drugs were left to individual clinical judgement. All patients were examined at one month intervals after PET studies. At each visit, an interim history was obtained and a neurological examination was performed. End points were defined as the occurrence of stroke or death. In patients with recurrent stroke, MRI or CT was obtained and compared with initial studies to confirm the occurrence of recurrent stroke. Stroke in the previously symptomatic arterial territory without evidence of primary intracranial haemorrhage was classified as an ipsilateral ischaemic stroke.

POSITRON EMISSION TOMOGRAPHY

Regional $\mathrm{CBF}, \mathrm{CMRO}_{2}, \mathrm{OEF}$, and $\mathrm{CBV}$ were measured with PET at the beginning of the observation period. In 24 patients studied between 1985 and 1989, PET was performed 
Table 2 Patients developing strokes during follow up

\begin{tabular}{|c|c|c|c|c|c|}
\hline Patient & $\begin{array}{l}\text { Age }(y) \\
\text { sex }\end{array}$ & Complications & Initial diagnosis & Location of infarct & Angiography \\
\hline $1^{\star}$ & $47 / M$ & HT & $\begin{array}{l}\text { Hemispheric TIAs, } \\
\text { Minor stroke }\end{array}$ & $\begin{array}{l}\mathrm{R} \text { corticosubcortical } \\
\text { ACA-MCA } \\
\text { watershed }\end{array}$ & $\begin{array}{l}\mathrm{R} \text { intracranial ICA } \\
\text { stenosis }(95 \%)\end{array}$ \\
\hline 2 & $58 / \mathrm{F}$ & $\mathrm{DM}$ & Minor stroke & $\begin{array}{l}\mathrm{R} \text { deep MCA } \\
\text { watershed }\end{array}$ & $\begin{array}{l}\mathrm{R} \text { intracranial ICA } \\
\text { stenosis }(95 \%)\end{array}$ \\
\hline 3 & $64 / M$ & HT, DM & $\begin{array}{l}\text { Hemispheric TIAs, } \\
\text { minor stroke }\end{array}$ & $\begin{array}{l}\text { L centrum } \\
\text { semiovale, } \\
\text { L occipital cortex }\end{array}$ & L ICA occlusion \\
\hline 4 & $74 / \mathrm{M}$ & none & $\begin{array}{l}\text { Amaurosis, minor } \\
\text { stroke }\end{array}$ & $R$ caudate head & R ICA occlusion \\
\hline 5 & $63 / F$ & HT & Minor stroke & $\begin{array}{l}\mathrm{R} \text { caudate head, } \mathrm{R} \\
\text { putamen, } \mathrm{R} \text { centrum } \\
\text { semiovale }\end{array}$ & $\begin{array}{l}\text { R MCA occlusion } \\
\text { L ICA stenosis }(60 \%)\end{array}$ \\
\hline 6 & $63 / \mathrm{M}$ & HT & $\begin{array}{l}\text { Hemispheric TIA, } \\
\text { minor stroke }\end{array}$ & L parietal subcortex & L ICA occlusion \\
\hline 7 & $63 / \mathrm{F}$ & $\mathrm{DM}$ & $\begin{array}{l}\text { Hemispheric TIA, } \\
\text { minor stroke }\end{array}$ & R parietal subcortex & $\begin{array}{l}\mathrm{R} \text { intracranial ICA } \\
\text { stenosis }(80 \%)\end{array}$ \\
\hline 8 & $60 / M$ & HT & $\begin{array}{l}\text { Hemispheric TIAs, } \\
\text { minor stroke }\end{array}$ & R centrum semiovale & $\begin{array}{l}\text { R ICA occlusion } \\
\text { L intracranial ICA } \\
\text { stenosis }(65 \%)\end{array}$ \\
\hline 9 & $58 / \mathrm{M}$ & none & Minor stroke & $\begin{array}{l}\text { R subcortical ACA- } \\
\text { MCA watershed }\end{array}$ & R ICA occlusion \\
\hline
\end{tabular}

with a Positologica III PET scanner and the remaining examinations between 1990 and 1994 were carried out with a PCT3600W, both manufactured by Hitachi Medical Co, Japan. Technical data regarding these two scanners are described elsewhere. ${ }^{78}$ Each device has four and seven rings and can obtain seven and 15 tomographic slices in a single scanning process. The best spatial resolution is 7.6 and $6.5 \mathrm{~mm}$ at full width half maximum at the centre of the scanning field, and the axial resolution is 12 and $7 \mathrm{~mm}$ at the centre. Before the study, a ${ }^{68}$ germanium $-{ }^{68}$ gallium transmission scan was performed for $20 \mathrm{~min}$ utes to allow attenuation correction. Cerebral blood flow was determined while the subject continuously inhaled $\mathrm{C}^{15} \mathrm{O}_{2}$ through a mask. Measurements of $\mathrm{CMRO}_{2}$ and OEF were obtained during continuous inhalation of ${ }^{15} \mathrm{O}_{2}$. Data were collected for five minutes. A single breath of $\mathrm{C}^{15} \mathrm{O}$ was used to measure $\mathrm{CBV}$. We calculated $\mathrm{CBF}, \mathrm{CMRO}_{2}$, and OEF by the steady state method, ${ }^{9}$ and $\mathrm{CMRO}_{2}$ and $\mathrm{OEF}$ were corrected by CBV. ${ }^{10}$ The ratio $\mathrm{CBF} / \mathrm{CBV}$ was calculated pixel by pixel as an indicator of cerebral perfusion reserve. ${ }^{11}$ All subjects and their relatives gave informed consent to the PET study.

We analysed three (Positologica III) or six (PCT3600W) tomographic planes located 43 to $82 \mathrm{~mm}$ above and parallel to the orbitomeatal line, which corresponded to the levels from the basal ganglia and thalamus to the centrum semiovale. The region of interest was placed on the CBF images and CT-PET imaging coregistration was not used. Each image was examined by placing a total of 18-20 circular regions of interest $10 \mathrm{~mm}$ in diameter over the cerebral cortex. According to the atlas developed by Kretschmann and
Weinrich, ${ }^{12}$ the regions of interest in all images included the distribution of the anterior cerebral artery (ACA), the MCA, and the posterior cerebral artery, as well as the watershed areas between the ACA and MCA (anterior watershed) and MCA and PCA (posterior watershed) ${ }^{13}$ In five patients with infarction in the cerebral cortex, the regions of interest corresponding to the infarcted area were excluded from analysis, by comparing PET images with CT or MRI. The mean hemispheric value was calculated as the average of the MCA, anterior watershed, and posterior watershed regions of interest, and was weighted by region size.

The haemodynamic state of cerebral circulation in the hemisphere ipsilateral to symptomatic ICA or MCA lesion was determined based on the value of OEF. Using PET, we studied 10 normal subjects, eight men and two women aged 35 to 78 (mean 52 (SD) 3) years. In five subjects (four men and one woman), PET was performed with a Positologica III PET scanner and the remaining five examinations were carried out with a PCT3600W. Although no significant differences were found in age or mean hemispheric $\mathrm{CBF}, \mathrm{CMRO}_{2}$, $\mathrm{OEF}, \mathrm{CBV}$, or $\mathrm{CBF} / \mathrm{CBV}$ values between these two populations (Student's $t$ test), PET data obtained by the camera with higher spatial resolution had a tendency to provide higher PET values. The normal values in 20 hemispheres ranged from $36 \cdot 1$ to $51 \cdot 7$ (mean 42.6 (SD 5.1)) \% for OEF. No significant difference among the individual regions of interest (MCA, anterior watershed, and posterior watershed) existed in this subgroup of normal subjects (analysis of variance with post hoc Scheffe's $F$ test). Absolute hemispheric values beyond the upper $95 \%$ confidence intervals defined in normal subjects (above 53.3\%) 
Table 2 continued

\begin{tabular}{|c|c|c|c|c|}
\hline \multirow[b]{2}{*}{ Collaterals } & \multirow{2}{*}{$\begin{array}{l}\text { Oxygen } \\
\text { extraction } \\
\text { fraction }\end{array}$} & \multicolumn{3}{|l|}{ Recurrent ischaemic stroke } \\
\hline & & $\begin{array}{l}\text { Side, type, and } \\
\text { location of infarct }\end{array}$ & $\begin{array}{l}\text { Interval after } \\
\text { PET (months) }\end{array}$ & Related conditions \\
\hline Leptomeningeal & Increased & $\begin{array}{l}\text { Ipsilateral, cortico- } \\
\text { subcortical MCA- } \\
\text { PCA watershed }\end{array}$ & 1 & Unknown \\
\hline $\begin{array}{l}\text { Ophthalmic } \\
\text { leptomeningeal }\end{array}$ & Increased & $\begin{array}{l}\text { Ipsilateral, lacune in } \\
\text { internal capsule }\end{array}$ & 1 & $\begin{array}{l}\text { Unknown } \\
\text { (poor control of DM) }\end{array}$ \\
\hline $\begin{array}{l}\text { A com } \\
\text { ophthalmic }\end{array}$ & Increased & $\begin{array}{l}\text { Ipsilateral, } \\
\text { subcortical ACA- } \\
\text { MCA watershed }\end{array}$ & 2 & $\begin{array}{l}\text { Unknown } \\
\text { (poor control of DM) }\end{array}$ \\
\hline A com & Increased & $\begin{array}{l}\text { Ipsilateral } \\
\text { subcortical ACA- } \\
\text { MCA watershed }\end{array}$ & 11 & Unknown \\
\hline Leptomeningeal & Increased & $\begin{array}{l}\text { Contralateral, striato- } \\
\text { capsular infarct }\end{array}$ & 11 & $\begin{array}{l}\text { Suspect dehydration } \\
\text { due to fever } \\
\text { (pyelonephritis)t }\end{array}$ \\
\hline P com & Normal & $\begin{array}{l}\text { Ipsilateral, } \\
\text { subcortical ACA- } \\
\text { MCA watershed }\end{array}$ & 2 & $\begin{array}{l}\text { Excessive drop in } \\
\text { blood pressure } \\
(108 / 64) \text {, anaemia }\end{array}$ \\
\hline Leptomeningeal & Normal & $\begin{array}{l}\text { Ipsilateral, cortico- } \\
\text { subcortical ACA- } \\
\text { MCA watershed }\end{array}$ & 2 & $\begin{array}{l}\text { Suspect dehydration } \\
\text { after hikingt }\end{array}$ \\
\hline A com & Normal & $\begin{array}{l}\text { Contralateral, } \\
\text { deep MCA } \\
\text { watershed }\end{array}$ & 30 & $\begin{array}{l}\text { Excessive drop in } \\
\text { blood pressure } \\
(130 / 50) \text {, dehydration } \\
\text { (PCV } 51 \cdot 4 \%) \text {, } \\
\text { Progression of the L } \\
\text { ICA stenosis }(90 \%)\end{array}$ \\
\hline A com & Normal & $\begin{array}{l}\text { Ipsilateral, small } \\
\text { frontoparietal } \\
\text { immediately- } \\
\text { subcortical infarcts }\end{array}$ & 57 & $\begin{array}{l}\text { Contralateral } \\
\text { intracranial ICA } \\
\text { Stenosis }(60 \%) \text { with } \\
\text { ulceration }\end{array}$ \\
\hline
\end{tabular}

were considered abnormal. The 40 patients were divided into two haemodynamic categories according to the OEF data: patients with normal OEF and those with increased OEF (misery perfusion).

\section{STATISTICAL ANALYSIS}

We compared the incidence of recurrent stroke in patients with normal OEF and that of those with increased OEF using Fisher's exact test; Significance was established at $\mathrm{P}<0.05$.

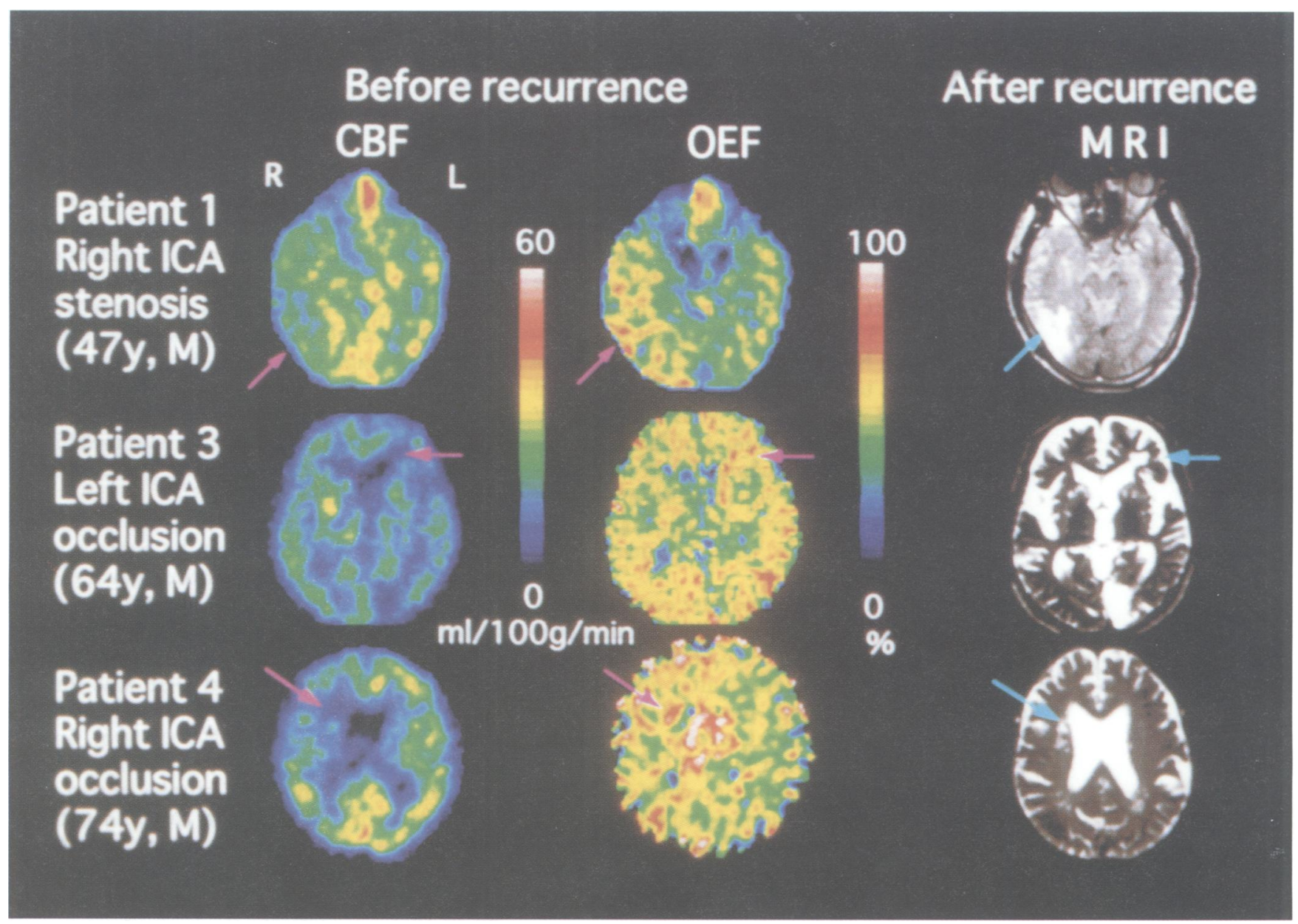

Figure 2 PET images of cerebral blood flow (CBF; first column) and oxygen extraction fraction (OEF; second column) before recurrence and T2 weighted MRI images (third column) after recurrence in three patients with increased OEF and ipsilateral recurrent stroke (watershed infarction) within the first year of follow up. Arrows indicate the site of recurrent stroke and corresponding areas on PET images. PET images of patient 1 were resliced for the coregistration to MRI. Numbers correspond to the patient numbers in table 2. 


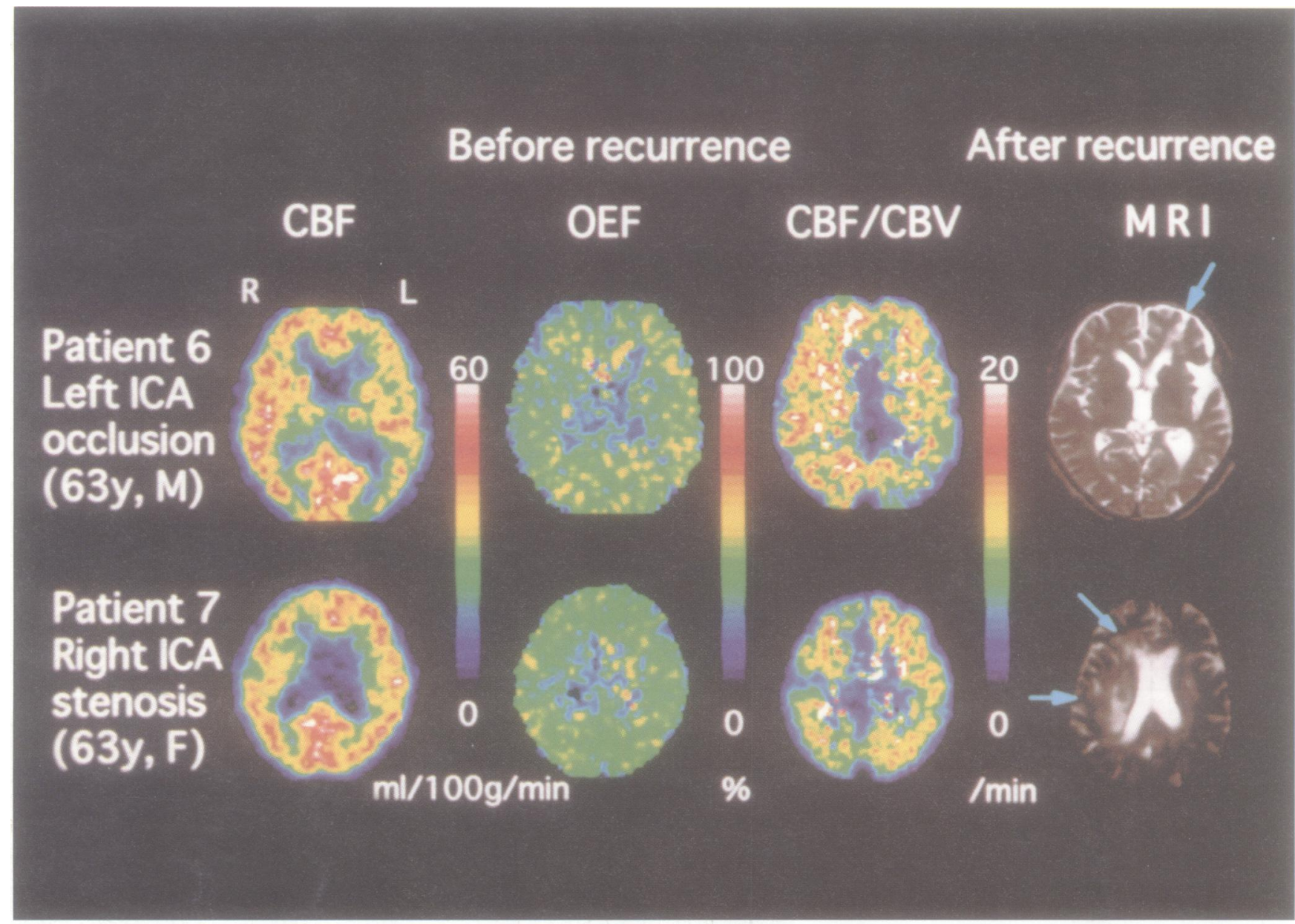

Figure $3 P E T$ of cerebral blood flow (CBF; first column) and oxygen extraction fraction (OEF; second column) and the ratio of cerebral blood flow to cerebral blood volume (CBF/CBV; third column) before recurrence and T2 weighted MRI images (fourth column) after recurrence in two patients with normal $O E F$ and ipsilateral recurrent stroke (watershed infarction) within the first year of follow up. Arrows indicate the site of recurrent stroke. Numbers correspond to the patient numbers in table 2.

\section{Results}

No patient showed a significant change in $\mathrm{PaCO}_{2}$ during PET. Based on PET measurements in the hemisphere supplied by the symptomatic ICA or MCA (in the "ipsilateral" hemisphere), 33 patients had normal OEF values and seven had increased OEF values (misery perfusion; table 1). Patients with increased OEF also had decreased $\mathrm{CBF}$ and $\mathrm{CBF} / \mathrm{CBV}$ values (fig 1). The OEF values of the asymptomatic ("contralateral") hemispheres were normal in all 33 patients with normal ipsilateral $\mathrm{OEF}$, whereas they were normal in four and increased in three in seven patients with increased ipsilateral OEF.

Seven (six ipsilateral and one contralateral) ischaemic strokes occurred within the first year of follow up (table 2). Five strokes occurred during the first two months after entering the study. Of patients with normal OEF values, two developed ipsilateral stroke. These two patients had a somewhat low $\mathrm{CBF} / \mathrm{CBV}$ value (fig 1, bottom). Of patients with increased OEF values, four developed ipsilateral stroke and one had stroke in the contralateral hemisphere with increased OEF. Because no deaths occurred within the first year, all 40 patients were at risk for 12 months. The one year incidence of stroke in patients with increased OEF was five of seven for all strokes and four of seven for ipsilateral ischaemic strokes. The one year incidence of stroke for patients with normal OEF was two of 33 for all strokes and ipsilateral ischaemic strokes. The incidence of ipsilateral ischaemic strokes in patients with increased OEF and normal OEF was $57 \cdot 1 \%$ and $6.0 \%$ respectively (Fisher's exact test; $P=$ $0.005)$. A significant difference was found between patients with ipsilateral stroke and those without in the value of OEF (mean 51.6 (SD 5.2) $v 45.5$ (SD 6.0)\%, Mann-Whitney $U$ test; $\mathrm{P}<0.05$ ) or $\mathrm{CBF} / \mathrm{CBV}$ (7.0 (SD 2.3) $v 9.4(\mathrm{SD} 2.0) / \mathrm{min}, \mathrm{P}<0.05)$.

All patients with recurrent stroke had minor stroke at entry. Minor stroke may carry a greater risk of recurrent stroke than transient ischaemic attacks. When 34 patients with minor stroke were analysed, the incidence of ipsilateral ischaemic strokes in patients with increased OEF and normal OEF was four of seven $(57 \cdot 1 \%)$ and two of $27(7 \cdot 2 \%)$, respectively (Fisher's exact test; $P=0.0096$ ). In our patients, the intervals between the most recent ischaemic event and PET studies varied (one to 55 months). When data from 33 patients with transient ischaemic attack or stroke within one year before entry were analysed, the results were three of five $(60 \%)$ and two of $28(7 \cdot 1 \%)$, respectively (Fisher's exact test; $P$ $=0.0165)$.

Although five of six patients with ipsilateral recurrent stroke had hypertension or diabetes, 
their presence was not related to recurrence of stroke. The incidence of ipsilateral ischaemic strokes in patients with hypertension or diabetes and that of those without either disease were five of 24 and one of 16 respectively (Fisher's exact test; $\mathrm{P}=0.3725$ ).

After the first year of follow up, two strokes occurred in 33 patients observed for more than one year without stroke. One stroke was ipsilateral and the other was a contralateral ischaemic stroke. One ipsilateral ischaemic stroke occurred in 31 patients with normal OEF. This was combined with progression of intracranial ICA stenosis on the contralateral side. One contralateral ischaemic stroke also occurred in 31 patients with normal OEF. In two patients with increased OEF, there were no strokes. Two patients died of non-cerebral causes after the first year of follow up.

A total of nine patients developed ischaemic stroke during the follow up period; seven ipsilateral and two contralateral (table 2). Seven strokes were suggested to be of haemodynamic origin from the location of infarct or the related conditions. All seven infarcts occurred in the superficial or deep watershed region. Among these, the locations of three ipsilateral strokes in patients with increased OEF corresponded to the area of increased OEF (fig 2). Although no apparent associated conditions were identified in these three strokes in patients with increased OEF, one contralateral stroke (in the hemisphere with increased OEF) in a patient with increased OEF and two ipsilateral (fig 3) and one contralateral stroke in patients with normal OEF were related to conditions leading to a deterioration of the haemodynamic status (table 2).

Only two patients (patients 1 and 8) with ICA stenosis and recurrent stroke underwent angiography at the time of recurrence. The severity of stenosis was unchanged in patient 1 , but it was increased in patient 8 . In patients 2 and 7 , the presence of flow void at the siphon of ICA on follow up MRI suggested that the stenoses did not become occlusions. In patient 5, no information was available about the contralateral ICA lesion.

\section{Discussion}

This study showed that patients with major cerebral arterial occlusive diseases and increased OEF (misery perfusion) have a high risk of recurrent ipsilateral ischaemic stroke during the first year of follow up, contradicting the results of a previous study. ${ }^{5}$ There were four ipsilateral strokes among seven patients with increased OEF and two ipsilateral strokes among 33 patients with normal OEF. The incidence of ipsilateral ischaemic stroke in patients with increased OEF was as high as $60 \%$, and was significantly higher than that in patients with normal OEF. After the first year of follow up, however, the risk of ipsilateral ischaemic stroke showed no relation to the severity of initial haemodynamic abnormality. Only one patient with normal OEF developed an ipsilateral stroke, which was combined with progression of contralateral ICA stenosis.
Evidence of abnormal cerebral haemodynamics from PET implies a vulnerability to reduction in cerebral perfusion pressure and a tendency to develop cerebral infarction due to haemodynamic factors. ${ }^{12}$ No study has, however, shown a high incidence of haemodynamic infarction in patients with major cerebral arterial occlusive diseases and abnormal cerebral haemodynamics. In our study, five of six ipsilateral recurrent strokes during the first year of follow up were watershed infarctions. The location of three strokes in patients with increased OEF corresponded to the area of increased OEF. Although no apparent associated conditions were identified in these strokes in patients with increased OEF, two strokes in patients with normal OEF (but somewhat low $\mathrm{CBF} / \mathrm{CBV}$ ) were related to conditions leading to deterioration in haemodynamic state; a reduction in systemic blood pressure or haemoconcentration due to dehydration. These findings suggest that patients with major cerebral arterial occlusive diseases have a tendency to develop haemodynamic infarctions with (in patients with normal OEF) or without (in patients with increased OEF) apparent additional causes of haemodynamic disturbance. In one study, watershed infarctions accounted for $72 \%$ of delayed strokes in patients with ICA occlusion. ${ }^{14}$ Associated conditions suggesting haemodynamic mechanisms included raised packed cell volume, severe heart disease with episodes of decreased output and syncope, and severe disease of the contralateral ICA. Appropriate treatment of the causes of systemic haemodynamic disturbance may be crucial in the management of patients with major cerebral arterial occlusive disease, especially patients with increased OEF. In patients with major cerebral arterial occlusive disease, individual treatment strategies according to the haemodynamic state of each patient may be needed, including consideration of the degree of hypertension control ${ }^{15}$ and the optimal packed cell volume. ${ }^{16}$ In our patients with follow up stroke, optimal treatment and good compliance might have prevented haemodynamic strokes.

Few studies have systematically investigated the relation between cerebral haemodynamics determined by PET and the subsequent risk of stroke. A longitudinal study by Powers et al did not show a relation between abnormal cerebral haemodynamics (abnormal CBV/ CBF ratio defined as outside normal range) and the subsequent occurrence of stroke. ${ }^{5}$ If patients with haemodynamic abnormality ranging from mild to severe, such as those with an abnormal CBV/CBF ratio, were considered as a group, they did not show a high risk for early stroke. A small subgroup of patients with increased OEF, however, could have an increased risk of developing a stroke, ${ }^{2}$ because both their study and ours included small patient samples and patient selection could have biased the outcome causing different results. The incidence of ipsilateral stroke within the first year in their study (one of 30) was apparently lower than that in our sample 
(six of 40) as well as that in the ExtracranialIntracranial Bypass Trial $(0 \cdot 109) .{ }^{56}$ In their study, most PET investigations were performed within 30 days after onset of the neurological symptoms, whereas our patients underwent PET studies at least one month after the most recent ischaemic event. After a stroke in major cerebral arterial occlusive diseases, intracranial collaterals may develop, and the initially impaired cerebral haemodynamics may improve during the next few months in some patients. ${ }^{17}$ Thus our patients with abnormal cerebral haemodynamics may include more patients with poor collateral development than were included in the comparable group in the study by Powers et al, ${ }^{5}$ leading to the higher risk for ischaemic stroke seen in our study. Moreover, two of five patients with intracranial ICA stenosis showed increased $\mathrm{OEF}$ and developed ipsilateral ischaemic strokes in our study, whereas a patient with intracranial ICA stenosis and normal haemodynamics was the only one to develop ipsilateral stroke in their study. Patients with symptomatic intracranial ICA stenosis are reported to have a high risk of stroke. ${ }^{6}$ The difference in haemodynamic state between these patients might have affected the results. Also, our study included more patients with minor strokes than the study by Powers et $a l,{ }^{5}$ and all patients with recurrence initially had minor strokes. Lastly, differences in medical treatment and patient compliance would affect the results. Irrespective of these differences, the combination of these two PET studies shows that ipsilateral strokes within the first year occurred in four of 12 patients with increased OEF, and three of 58 patients with normal OEF. There is still a significant relation between the incidence of ipsilateral recurrent strokes and increased OEF (Fisher's exact test; $P=0.0139$ ).

Recent studies of larger samples of patients using SPECT and intravenous injection of acetazolamide $^{1819}$ or transcranial Doppler sonography and $\mathrm{CO}_{2}$ inhalation ${ }^{20}$ have disclosed that a small subgroup of patients with highly impaired cerebrovascular reactivity at entry had an increased risk of developing a stroke during the follow up period. A close relation has been shown between impaired cerebrovascular reactivity measured by both stimuli and increased $\mathrm{OEF},{ }^{21-23}$ supporting the finding that patients with increased OEF have a high risk of stroke. Other findings suggesting misery perfusion include $(a)$ very low $\mathrm{CBF} /$ $\mathrm{CBV}$ ratio, ${ }^{11}$ (b) poor collateral circulation through leptomeningeal anastomoses, ${ }^{24-26}$ (c) decreased CBF without contralateral cerebellar hypoperfusion. ${ }^{27} 28$

In conclusion, in our small, selected patient sample, patients with major cerebral arterial occlusive diseases and increased OEF (misery perfusion) showed a high risk of recurrent ipsilateral ischaemic strokes. Thus identification and optimal treatment of patients with this problem may be essential in preventing recurrent stroke. Firstly, the control and elimination of risk factors are desirable, but excessive falls in blood pressure must be avoided. ${ }^{151720}$
Secondly, the causes of systemic haemodynamic disturbance such as dehydration and heart failure must be treated appropriately. Thirdly, besides antiplatelet treatment, specific medical treatments including haemodilution $^{16}$ and specific drugs ${ }^{29}$ may be beneficial. Lastly, patients not responding to current medical treatment might be indicated for vascular reconstructive surgery. We must seek the optimal medical treatment for patients with major cerebral arterial occlusive disease based on the haemodynamic state of each patient.

This work was supported by Scientific Research grants (C05670556, A-04404043) from the Japanese Ministry of Education, Science and Culture.

We thank the staff of the Department of Radiology and Nuclear Medicine, Faculty of Medicine, Kyoto University (Drs Sadahiko Nishizawa, Yasushi Iwasaki, Norihiro Sadato, Yasuhiro Magata, Koichi Ishizu, and Hidehiko Okazawa) for their support and technical help. We also thank Drs Naoki Fujimoto, Kiyoshi Harada, Shinya Yamaguchi, Masafumi Ogawa, Yasuomi Ouchi, Shigeru Matsuzaki, Tadashi Ino, and Kaiyo Oiwa for their cooperation.

1 Baron JC, Bousser MG, Rey A, Guillard A, Comar D, Castaigne P. Reversal of focal "misery-perfusion synCastaigne P. Reversal of focal "misery-perfusion synnamic cerebral ischemia. A case study with ${ }^{15} \mathrm{O}$ positron namic cerebral ischemia. A case study with
emission tomography. Stroke $1981 ; 12: 454-9$.

2 Powers WJ. Cerebral hemodynamics in ischemic cerebrovascular disease. Ann Neurol 1991;29:231-40.

3 Samson Y, Baron JC, Bousser MG, et al. Effects of extraintracranial arterial bypass on cerebral blood flow and oxygen metabolism in humans. Stroke 1985;16:609-16.

4 Gibbs JM, Wise RJS, Thomas DJ, Mansfield AO, Russell RWR. Cerebral haemodynamic changes after extracranialintracranial bypass surgery. $\mathcal{F}$ Neurol Neurosurg Psychiatry 1987;50:140-50.

5 Powers WJ, Temple LW, Grubb RLJ. Influence of cerebral hemodynamics on stroke risk: one year follow-up of 30 hemodynamics on stroke risk: one year follow-up of 30
medically treated patients. Ann Neurol 1989;25:325-30.

6 The EC/IC Bypass Study Group. Failure of extracranialintracranial arterial bypass to reduce the risk of ischemic stroke. Results of an international randomized trial. $\mathrm{N} \mathrm{Engl}$ stroke. Results of an internatio.

7 Senda M, Tamaki N, Yonekura Y, et al. Performance characteristics of Positlogica III: a whole-body positron emission tomograph. 7 Comput Assist Tomogr 1985;9:940-6.

8 Sadato N, Yonekura Y, Senda M, et al. PET and the autoradiographic method with continuous inhalation of oxygen15-gas: theoretical analysis and comparison with conventional steady-state methods. F Nucl Med 1993; 34:1672-80.

9 Frackowiak RSJ, Lenzi GL, Jones T, Heather JD. Quantitative measurement of regional cerebral blood flow and oxygen metabolism in man using ${ }^{15} \mathrm{O}$ and positron emission tomography: theory, procedure, and normal values. $f$ tomography: theory, procedure, and
Comput Assist Tomogr 1980;4:727-36.

10 Lammertsma AA, Jones T. Correction for the presence of intravascular oxygen-15 in the steady-state technique for measuring regional oxygen extraction ratio in the brain: 1 Description of the method. $f$ Cereb Blood Flow Metab 1983;3:416-24

11 Gibbs JM, Wise RJS, Leenders KL, Jones T. Evaluation of cerebral perfusion reserve in patients with carotid artery occlusion. Lancet 1984;1:310-4.

12 Kretschmann HJ, Weinrich W, eds. Neuroanatomy and cranial computed tomography. New York: Thieme Inc, 1986: $70-4$

13 Yamauchi H, Fukuyama H, Kimura J, Konishi J, Kameyama $M$. Hemodynamics in internal carotid artery occlusion examined by positron emission tomography. Stroke 1990;21:1400-6.

14 Bogousslavsky J, Regli FA. Borderzone infarctions distal to internal carotid artery occlusion: prognostic implications. internal carotid artery occlusion
Ann Neurol 1986;20:346-50.

15 Irie K, Yamaguchi T, Minematsu K, Omae T. The J-curve phenomenon in stroke recurrence. Stroke 1993;24: phenomenc.

16 Yamauchi H, Fukuyama H, Ogawa M, Ouchi Y, Kimura J. Hemodilution improves cerebral hemodynamics in internal carotid artery occlusion. Stroke 1993;24:1885-90.

17 Widder B, Kleiser B, Krapf $\mathrm{H}$. Course of cerebrovascular reactivity in patients with carotid artery occlusions. Stroke 1994;25:1963-7.

18 Yonas H, Smith HA, Durham SR, Pentheny SL, Johnson DW. Increased stroke risk predicted by compromised cerebral blood flow reactivity. $\mathcal{F}$ Neurosurg 1993;79:483-9.

19 Kuroda S, Kamiyama H, Abe H, Houkin K, Isobe M Mitsumori K. Acetazolamide test in detecting reduced cerebral perfusion reserve and predicting long-term prognosis in patients with internal carotid artery occlusion. Neurosurgery 1993;32:912-8. 
20 Kleiser B, Widder B. Course of carotid artery occlusions with impaired cerebrovascular reactivity. Stroke 1992;23: $171-4$

21 Kanno I, Uemura K, Higano S, et al. Oxygen extraction fraction at maximally vasodilated tissue in the ischemic brain estimated from the regional $\mathrm{CO}_{2}$ responsiveness measured by positron emission tomography. $\mathcal{F}$ Cereb Blood Flow Metab 1988;8:227-35.

22 Herold S, Brown MM, Frackowiak RSJ, Mansfield AO, Thomas DJ, Marshall J. Assessment of cerebral haemodynamic reserve: correlation between PET parameters and $\mathrm{CO}_{2}$ reactivity measured by the intravenous ${ }^{133}$ xenon injec-
tion technique. $f$ Neurol Neurosurg Pychiatry 1988;

23 Hirano T, Minematsu K, Hasegawa Y, Tanaka Y, Hayashida K, Yamaguchi T. Acetazolamide reactivity on 123I-IMP single photon emission computed tomography in patients with major cerebral artery occlusive disease: correlation with positron emission tomography parameters. $\mathcal{F}$ Cereb Blood Flow Metab 1994;14:763-70.

24 Sgouropoulos P, Baron JC, Samson Y, Bousser MG, Comar $D$, Castaigne P. Long-term effects of stenosis and occlusion of the middle cerebral artery on regional cerebral blood flow and oxygen metabolism: a positron tomography study. Rev Neurol 1985;141:698-705.
25 Powers WJ, Press GA, Grubb RL, Gado M, Raichle ME. The effect of hemodynamically significant carotid artery disease on the hemodynamic status of the cerebral circulation. Ann Intern Med 1987;106:27-35.

26 Yamauchi H, Fukuyama H, Nabatame H, Fujimoto N Kimura J. Significance of low perfusion with increased oxygen extraction fraction in a case of internal carotid artery stenosis. Stroke 1992;23:431-2.

27 Yamauchi H, Fukuyama H, Yamaguchi S, et al. Crossed cerebellar hypoperfusion in unilateral major cerebral artery occlusive disorders. $\mathcal{f}$ Nucl Med 1992;33: artery $1632-6$.

28 Yamauchi $H$, Fukuyama $H$, Kimura J, Ishikawa $M$, Kikuchi $H$. Crossed cerebellar hypoperfusion indicates the degree of uncoupling between blood flow and metabolism in of uncoupling between blood flow and metabolism in major

29 Yamaguchi S, Fukuyama H, Kimura J, Yonekura Y, Konishi $\mathrm{J}$. Effect of brovincamine on cerebral circulation and metabolism in internal carotid artery occlusion examined by positron emission tomography. Eur Neurol 1992;32: 314-7.

30 Fukuyama H, Kimura J, Yamaguchi S, et al. Pharmacological effects of ibudilast on cerebral circulation: a PET study. Neurol Res 1993;15:169-73.

\section{NEUROLOGICAL STAMP}

\section{Louis Charles Alfred de Musset (1810-57)}

After a brilliant scholastic career at the Lycée Henri IV, Musset, French poet, novelist, and playwright, briefly considered law and medicine as a career. He dabbled in painting before finally turning to literature. Musset contracted syphilis as a young man, which led to his early death. The syphilis caused an aortic aneurysm and aortic insufficiency. He developed a rhythmic movement of his head synchronous with his heartbeat. This phenomenon became eponymically known as Musset's sign and was first described by A Delpech. Philatelically he was honoured as a great poet but is of medical interest because of Musset's sign. He was honoured by his native country, France, in 1951. The stamp shown here is one produced by Romania in 1960 (Stanley Gibbons 2763, Scott 1343). Two colleagues Anton Chekov and Robert Koch are portrayed in the same series.

L F HAAS

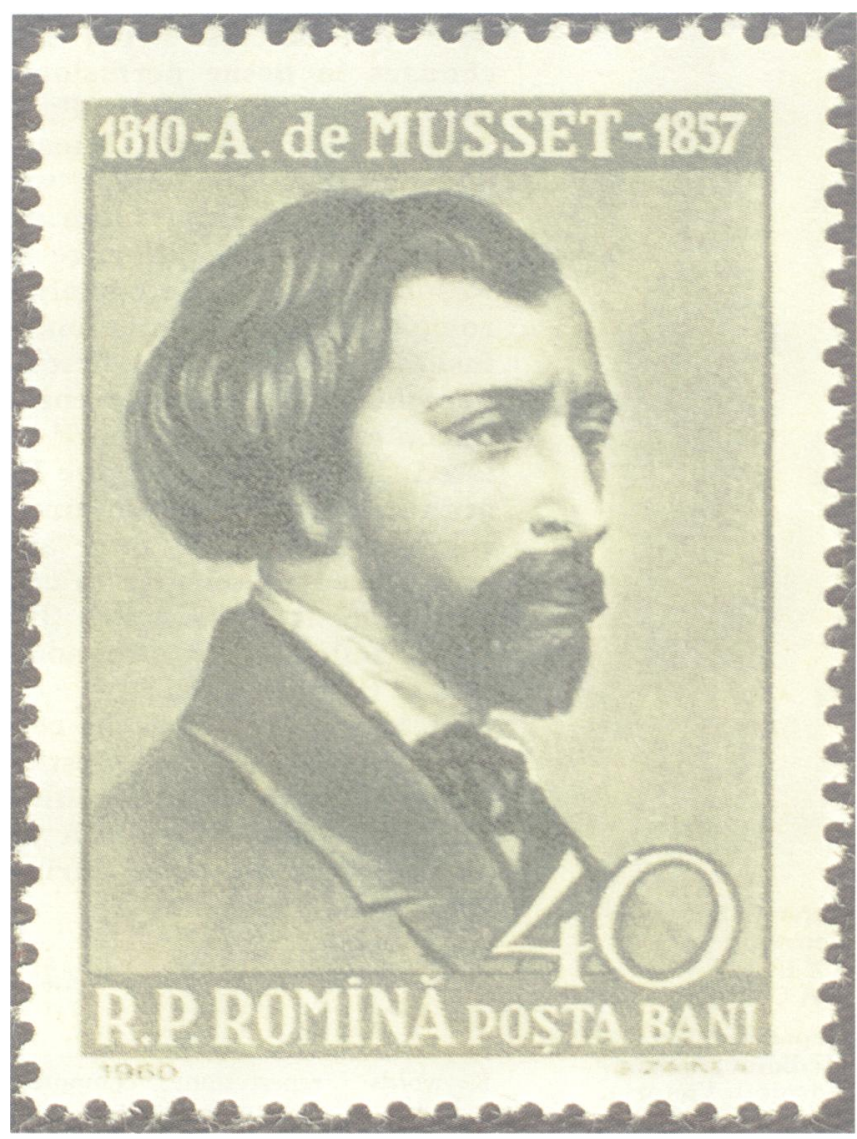

